\title{
Performance of flow and heat transfer analysis of mixed convection in Casson fluid filled lid driven cavity including solid obstacle with magnetic impact
}

\author{
Mohammad Mokaddes Ali ${ }^{1} \cdot$ Rowsanara Akhter $^{2} \cdot$ M. A. Alim ${ }^{3}$
}

Received: 4 September 2020 / Accepted: 19 January 2021 / Published online: 1 February 2021

(c) The Author(s) 2021 OPEN

\begin{abstract}
In this study, the heat transfer and fluid flow characteristics of mixed convection in a double lid driven cavity containing a heat conducting solid obstacle in presence of magnetic field is numerically investigated. The left and right vertical walls of the cavity are isothermally heated and cooled respectively while horizontal walls are thermally insulated. A solid cylinder is positioned at the centre of the cavity. Mathematical model has been developed considering non-Newtonian model of Casson fluid and solved with finite element method based on Galerkin residual technique. The simulated numerical results are obtained through streamlines, temperature contours and average Nusselt number for a set of dimensionless parameters and discussed elaborately to make the effective usability of Casson fluid in different industrial and engineering processes. The obtained results based on special cases are compared with the existing results. It is observed that the flow and thermal fields were influenced significantly by the Reynolds number for any Casson fluid parameter. The intensification of streamlines strengthened for Casson fluid parameter compared to isotherms. Moreover, enhancement of heat transfer due to increased Reynolds number expedites with Casson fluid parameter while a reverse trend is observed for higher Hartmann number. In addition, appropriate direction of lid walls provides a better heat transfer rate.
\end{abstract}

Keywords Mixed convection · Casson fluid · Magnetic field · Finite element method · Solid obstacle · Lid driven cavity

$\begin{array}{ll}\text { List of symbols } \\ c_{p} \quad \text { Specific heat at constant pressure }\left(\mathrm{kg}^{-1} \mathrm{~K}^{-1}\right) \\ g & \text { Gravitational acceleration }\left(\mathrm{ms}^{-2}\right) \\ \mathrm{Gr} & \text { Grashof number }\left(g \beta_{\mathrm{f}}\left(\mathrm{T}_{\mathrm{h}}-\mathrm{T}_{\mathrm{c}} \mathrm{L}^{3} / \mathrm{v}_{\mathrm{f}}\right)\right. \\ \mathrm{Ha} & \text { Hartmann number }\left(\mathrm{B}_{0} \mathrm{I}\left(\sigma_{\mathrm{f}} / \mu_{\mathrm{f}}\right)^{112}\right) \\ \mathrm{L} & \text { Length of the Cavity }(\mathrm{m}) \\ k & \text { Thermal conductivity of fluid }\left(\mathrm{Wm}^{-1} \mathrm{~K}^{-1}\right) \\ \mathrm{K} & \text { Thermal conductivity ratio } \\ \mathrm{Nu} & \text { Nusselt number } \\ \mathrm{Pr} & \text { Prandtl number } \operatorname{Pr}=\mathrm{vf} / \mathrm{a}_{\mathrm{f}} \\ \mathrm{p} & \text { Dimensional pressure }\left(\mathrm{Nm}^{-2}\right) \\ \mathrm{P} & \text { Dimensionless pressure } \\ q_{w} & \text { Heat flux }\left(\mathrm{Wm}^{-2}\right) \\ \mathrm{Re} & \text { Reynolds number }\left(\mathrm{g} \beta_{\mathrm{f}}\left(\mathrm{T}_{\mathrm{h}}-\mathrm{T}_{\mathrm{c}} \mathrm{L}^{3} / \mathrm{v}_{\mathrm{f}}\right)\right.\end{array}$

\section{List of symbols}

c

$\mathrm{Ha}$

$\mathrm{L}$

$\mathrm{Nu}$

Pr
$T \quad$ Dimensional temperature $(\mathrm{K})$

$u, v \quad$ Dimensional velocity components $\left(\mathrm{ms}^{-1}\right)$

$U, V$ Dimensionless velocity components

$x, y \quad$ Dimensional coordinates $(\mathrm{m})$

$X, Y$ Dimensionless coordinates

\section{Greek symbols}

a Fluid thermal diffusivity $\left(\mathrm{m}^{2} \mathrm{~s}^{-1}\right.$

$\beta_{\text {TEC }}$ Thermal expansion coefficient $\left(\mathrm{K}^{-1}\right)$

$\beta \quad$ Casson fluid parameter

$\theta \quad$ Dimensionless temperature $\theta=\left(T-T_{c}\right) /\left(T_{h}-T_{c}\right)$

$\mu \quad$ Dynamic viscosity $\left(\mathrm{Nsm}^{-2}\right)$

$v \quad$ Kinematic viscosity $\left(\mathrm{m}^{2} \mathrm{~s}^{-1}\right)$

$\rho \quad$ density $\left(\mathrm{kgm}^{-1}\right)$

$\triangle$ Mohammad Mokaddes Ali, mmali309@gmail.com | 'Department of Mathematics, Mawlana Bhashani Science and Technology University, Tangail, Bangladesh. ${ }^{2}$ Department of Electrical and Electronic Engineering, International University of Scholars, Dhaka, Bangladesh. ${ }^{3}$ Department of Mathematics, Bangladesh University of Engineering and Technology, Dhaka, Bangladesh. 


$\begin{array}{ll}\text { Subscripts } \\ \text { av } & \text { average } \\ h & \text { hot } \\ c & \text { cold } \\ f & \text { fluid } \\ c f & \text { Casson fluid } \\ s & \text { solid } \\ \text { lid } & \text { Lid wall }\end{array}$

\section{Introduction}

Heat transfer analysis for mixed convection in lid driven cavities is of great significance as it is frequently encountered in engineering applications such as cooling of electronic and microelectronic components, heat exchangers, thermal designing of buildings, nuclear reactors, solar collectors, float glass production and food processing, etc. The interaction of buoyancy driven force along with shear driven force causes an enhancement in flow circulation and temperature distributions within the enclosure. In addition, the complex interaction between the buoyancy force and Lorentz's force due to presence of magnetic field effect has an impact to control the flow and heat transport processes. Accordingly, detailed analysis of the flow and heat transport characteristics for such processes is important for better designing of engineering and industrial equipment. In this context, numerical and experimental researches have been conducted for mixed convection in lid driven cavities where magnetic field effect was either considered or not.

Basak et al. [1] presented a detailed numerical analysis of lid driven flow pattern and heat transfer rate in a square cavity. The flow pattern was dominated by effect of the governing parameters. Heat transfer rate was higher at the edge and lower at the centre of the bottom wall for uniform heating case. Mahmoodi [2] developed a numerical code using finite volume approach with SIMPLER algorithm to analyze flow and heat transfer in a lid driven rectangular cavity. He demonstrated that the heat transfer rate and flow vertex affected with the aspect ratio along with Richardson number. Fereidoon et al. [3] implemented similar mathematical technique [2] to investigate mixed convection in an inclined lid driven cavity and found the flow pattern changed radically with greater inclination angle of the cavity. Later on, Abu-Nada and Chamkha [4] utilized second order accurate finite volume method to develop numerical model for mixed convection in a wavy walled lid driven cavity. They reported that wavy wall enhances the heat transfer rate. A lattice Boltzmann solution was performed by Ekici [5] using Newtonian fluid to improve the heat transfer process. Rabani [6] conducted a numerical study of mixed convection in a lid driven triangular cavity and observed highest heat transfer occurs for assisting mixed convection flow. The problem of mixed convection in a square cavity having a rotating cylinder and flexible side wall was numerically investigated by Alsabery et al. [7]. They found that heat transfer rate increases with Rayleigh number and it was also maximum in counter clockwise rotation of the cylinder. Ali et al. [8, 9] analyzed the effects of magnetic field on mixed and natural convection flow for different geometries. Selimefendigil and Öztop [10] studied magnetic field effect on mixed convection in a lid driven cavity and revealed that the magnetic field effect decreases the average heat transfer rate. Finite volume method based numerical simulation [11] pointed out that the heat transfer rate becomes increasing function of magnetic inclination angle. Another numerical simulation [12] illustrated that the effect of magnetic field on the local heat transfer rate depend on suitable combinations of flow parameters. Selimefendigil and Oztop [13] studied the effect of inclined magnetic field on forced convection flow over a corrugated channel. They found that average Nusselt number is higher in pulsating flow than steady flow. It was also noted that the presence of magnetic field at $\mathrm{Ha}=15$ reduces the heat transfer rate remarkably. Later on, they [14] investigated the effect of magnetic field on mixed convection due to double rotating cone in a 3D enclosure and recommended that magnetic field reduces the convection effect, and average Nusselt number significantly improved with the size and speed of rotating cones.

In addition, abstractions of various shaped within closed or open enclosure are used to control the flow circulation and temperature distribution within enclosure. Several studies have been accomplished related to the natural/mixed/forced convection flow in presence of different abstractions. House et al. [15] numerically examined the fluid flow and heat transfer processes for natural convection in square cavity with centered square obstacle and recommended that heat transfer rate decreases with increase in size of the obstacle. The problem of mixed convection flow around a circular obstruction within a rectangular cavity was numerically studied by Rahman et al. [16] to visualize the effect of size, location and thermal conductivity of solid obstacle on the heat transfer process. They found flow and average Nusselt significantly affected with the mentioned parameters. Islam et al. [17] developed a computational code to analyze mixed convection in a square cavity in presence of a heated centered square blockage. They noted that heat transfer rate decreases with increasing blockage ratio for a fixed Richardson number. Later on, Bourada et al. [18] utilized Lattice Boltzmann method to investigate mixed convection in lid driven cavity containing a porous obstacle and found that heat transfer is important for a small reduction in obstacle size.

Recently, non-Newtonian fluids become an interesting topic to the researchers because of its scientific and 
engineering applications compared to Newtonian fluids. In this regards, Casson (1995) developed a new class of fluid which doesn't follow the Newton's law of viscosity named as non-Newtonian Casson fluid or simple as Csaaon fluid. He found that it is more appropriate for rheological data compared to other non-Newtonian fluids. Some of the numerical analysis of Casson fluid flow have been reported here. Pop and Sheremet [19] analyzed free convection in a differentially heated square cavity filled with Casson fluid. Their results indicated the flow and heat transfer rate increases with Casson fluid parameter. The heat transfer rate due to variation of Pr accelerated for greater values of Casson fluid parameter. Reddy et al. [20] numerically studied heat transfer visualization for free convective non-Newtonian Casson fluid flow over a cylinder. They suggested that average Nusselt number escalates with increasing Casson fluid parameter. Later on, A numerical investigation on free convection flow of Casson fluid in a trapezoidal cavity was reported by Hamid et al. [21] and found that average Nusselt shows an increasing behavior for rising Rayleigh number, Casson fluid parameter and heater length. Reza et al. [22] used shooting method to obtain multiple solutions for mixed convection flow of Casson fluid through a channel under the effects of magnetic field. The velocity profiles were increased for Casson fluid parameter in this investigation.

From the above literature survey, it is evident that numerous attentions have been given on experimental and theoretical works using Newtonian fluid but a less attention has been given in using of non-Newtonian fluid. From the technological point of view non-Newtonian Casson fluids play important roles in flow and temperature behaviors within closed enclosure. In this context, we have considered mixed convection in non-Newtonian Casson fluid filled lid driven square cavity having a centered solid obstacle under the effect of magnetic field. However, to the best of our knowledge the problem of mixed convection in double lid driven square cavities filled with Casson fluid has not been considered yet. The flow and thermal fields within the cavity are analyzed in terms of streamlines and isotherms for a range of important dimensionless parameters such as Reynolds number, Casson fluid parameter and Hartmann number. Heat transfer rate is also analyzed using average Nusselt number in this study.

This study has been organized in five sections: Sect. 2 represents the physical model of this investigation; Sect. 3 deals with the formulation of the governing equations based on Casson fluid model; Sect. 4 is dedicated to results and discussion, and finally concluding marks are summarized in Sect. 5.

\section{Physical model}

The physical model of this study is developed for a square cavity of length $L$ with two moving walls. A solid heat conducting circular obstacle is positioned at the center of the cavity. The vertical walls are in moving conditions which are respectively heated and cooled at temperature $T_{h}$ and $T_{c}$. The horizontal walls are kept adiabatic which are in no-slip conditions. Rectangular coordinate system $(x, y)$ is considered where the gravitational acceleration is acted along reversal of vertical direction. Magnetic field with uniform strength is imposed transverse to the buoyancy force. The schematic configuration of this investigation is given in Fig. 1.

\section{Mathematical analysis}

The governing conservation equations based on the physical model along with Boussinesq approximation can be written as follows $[8,10,16,19,21]$ :

$$
\frac{\partial u}{\partial x}+\frac{\partial v}{\partial y}=0
$$

$$
\begin{aligned}
u \frac{\partial u}{\partial x}+v \frac{\partial u}{\partial y}= & -\frac{1}{\rho} \frac{\partial p}{\partial x}+\frac{\mu}{\rho}\left(1+\frac{1}{\beta}\right)\left(\frac{\partial^{2} u}{\partial x^{2}}+\frac{\partial^{2} u}{\partial y^{2}}\right) \\
u \frac{\partial v}{\partial x}+v \frac{\partial v}{\partial y}= & -\frac{1}{\rho} \frac{\partial p}{\partial y}+\frac{\mu}{\rho}\left(1+\frac{1}{\beta}\right)\left(\frac{\partial^{2} v}{\partial x^{2}}+\frac{\partial^{2} v}{\partial y^{2}}\right) \\
& +\frac{1}{\rho}\left[g \beta \rho\left(T-T_{c}\right)\right]-\frac{\sigma}{\rho} B_{0}^{2} v
\end{aligned}
$$

$u \frac{\partial T}{\partial x}+v \frac{\partial T}{\partial y}=\frac{k}{\left(\rho C_{p}\right)}\left(\frac{\partial^{2} T}{\partial x^{2}}+\frac{\partial^{2} T}{\partial y^{2}}\right)$

$k_{s}\left(\frac{\partial^{2} T_{s}}{\partial x^{2}}+\frac{\partial^{2} T_{s}}{\partial y^{2}}\right)=0$

The boundary conditions using physical model are:

$$
u=0, v=0, \frac{\partial T}{\partial y}=0 ; y=0 \text { and } y=1
$$

\section{- Casel}

$u=0, v=1, T=T_{h}, x=0$ and $u=0, v=1, T=T_{c} ; x=1$ 
Fig. 1 Physical model of the present study
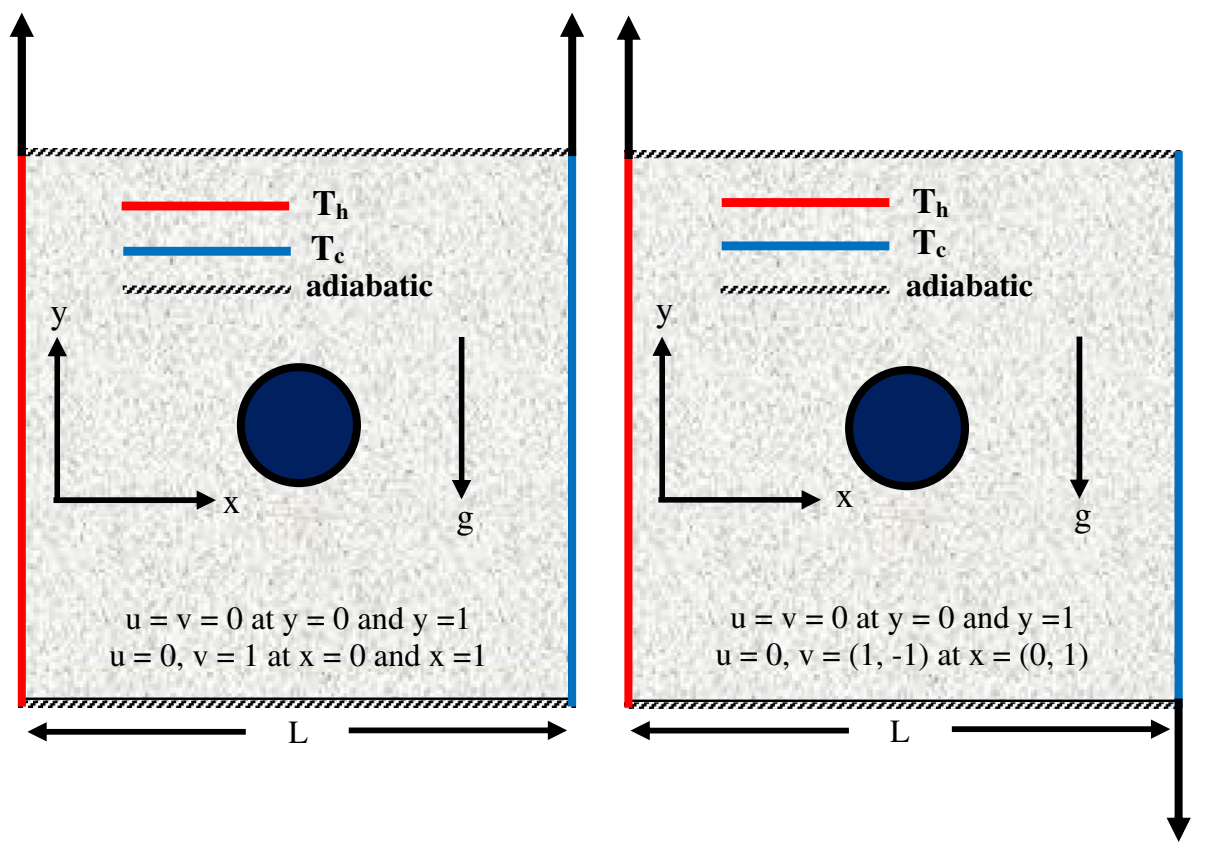

- Case ll

$u=0, v=1, T=T_{h}, x=0$ and $u=0$,

$v=-1, T=T_{c} ; x=1$

At the interface of fluid and solid obstacle:

$u=0, v=0$ and $\left(\frac{\partial T_{c f}}{\partial n}\right)=K\left(\frac{\partial T_{s}}{\partial n}\right)$

The following usual quantities are used to obtained dimensionless governing equations.

$X=\frac{x}{L}, Y=\frac{y}{L}, U=\frac{u}{U_{\text {lid }}}, V=\frac{v}{U_{\text {lid }}}, P=\frac{p}{\rho_{\text {nf }} U_{\text {lid }}^{2}}$ and $\theta=\frac{T-T_{c}}{T_{h}-T_{c}}$

and the resulting non dimensional governing equations are:

$\frac{\partial U}{\partial X}+\frac{\partial V}{\partial Y}=0$

$U \frac{\partial U}{\partial X}+V \frac{\partial U}{\partial Y}=-\frac{\partial P}{\partial X}+\frac{1}{\operatorname{Re}}\left(1+\frac{1}{\beta}\right)\left(\frac{\partial^{2} U}{\partial X^{2}}+\frac{\partial^{2} U}{\partial Y^{2}}\right)$

$$
\begin{aligned}
U \frac{\partial V}{\partial X}+V \frac{\partial V}{\partial Y}= & -\frac{\partial P}{\partial Y}+\frac{1}{\operatorname{Re}}\left(1+\frac{1}{\beta}\right)\left(\frac{\partial^{2} V}{\partial X^{2}}+\frac{\partial^{2} V}{\partial Y^{2}}\right) \\
& +\frac{G r}{\operatorname{Re}^{2}} \theta-\frac{H a^{2}}{\operatorname{Re}} V
\end{aligned}
$$

$$
U \frac{\partial \theta}{\partial X}+V \frac{\partial \theta}{\partial Y}=\left(\frac{1}{\operatorname{Re} \operatorname{Pr}}\right)\left(\frac{\partial^{2} \theta}{\partial X^{2}}+\frac{\partial^{2} \theta}{\partial Y^{2}}\right)
$$

$$
\left(\frac{\partial^{2} \theta_{s}}{\partial X^{2}}+\frac{\partial^{2} \theta_{s}}{\partial Y^{2}}\right)=0
$$

The boundary conditions (Eqs.6-9) are converted to the following form:

$U=0, \quad V=0, \frac{\partial \theta}{\partial Y}=0 ; Y=0$ and $Y=1$

- Casel

$U=0, V=1, \theta=1, X=0$ and

$U=0, V=1, \theta=0, X=1$

- Casell

$U=0, V=1, \theta=1, X=0$ and

$U=0, V=-1, \theta=0, X=1$

At the interface of fluid and solid obstacle:

$U=0, V=0$ and $\left(\frac{\partial \theta}{\partial N}\right)_{c f}=K\left(\frac{\partial \theta_{s}}{\partial N}\right)_{\text {solid }}$ 


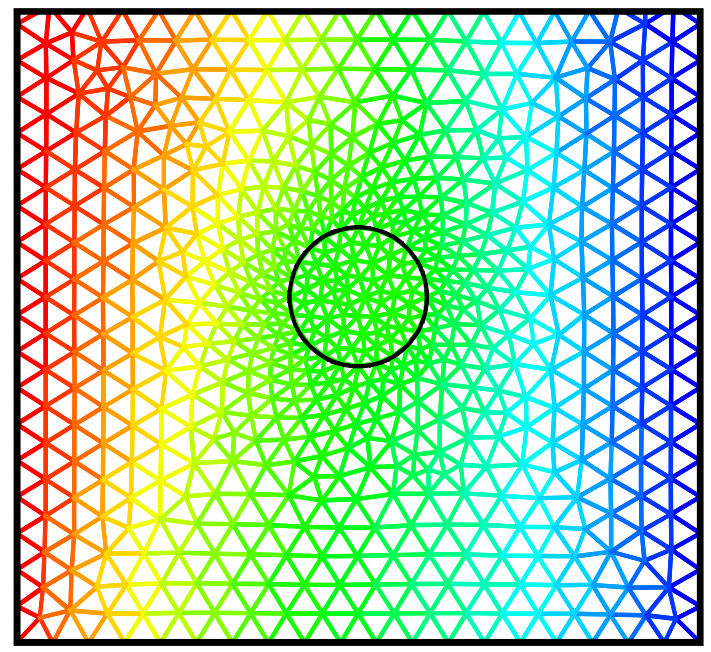

Fig. 2 Mesh generation of the square cavity

\subsection{Evaluation of local and average Nusselt number}

The important feature of our investigation is the heat transfer rate which is to be estimated using local Nusselt number for the heated wall. Accordingly, the local Nusselt number can be defined in dimensionless form as [23]:

$N u=-\frac{\partial \theta}{\partial X}$

and the average Nusselt number can be calculated by the following relation [23]:

$N u_{a v}=\frac{1}{L} \int_{0}^{1} N u d Y$

\subsection{Computational procedure}

Galerkin's weighted residual based finite element method has been exercised to simulate the momentum and energy equations. In this simulation, the solution domain is discretized by finite element mesh considering non-uniform triangular elements. Galerkin residual method has been implemented to convert the governing partial differential equations (Eqns. 11-15) into integral equations and then modified using Gauss's quadrature method which are transformed into linear algebraic equations and solved by Triangular Factorization Technique [24]. The detail computational procedure is available in Ali et al. [9] which was not repeated here. It is also well described by Taylor and Hood [25] and Dechaumphai [26]. The numerical results have been plotted using TECHPLOT 10 software.

\subsection{Mesh generation}

To implement the finite element method the geometric domain is divided into a set of sub-domains which are called finite element. It is mostly a discrete presentation of a solution domain where the problem is to be solved. The mesh configuration with triangular elements of this investigation has been shown in Fig. 2 .

\subsection{Grid sensitivity test}

The grid independent test has been performed by calculating average Nusselt number at different mesh size and presented in Table 1, 2 and Fig. 3, 4respectively. In calculating average Nusselt number, no significant changes were found for further increment in mesh levels. Thus, the grid size of 15,079 nodes and 29,178 elements should be selected to simulate the present problem.

Table 1 Grid sensitivity test at $\operatorname{Pr}=20, \operatorname{Re}=10, \mathrm{Ha}=10$ and $\beta=0.5$

\begin{tabular}{lllllll}
\hline Nodes (elements) & $4802(9150)$ & $6912(13,258)$ & $9787(18,858)$ & $12,558(24,258)$ & $15,079(29,178)$ & $17,780(34,442)$ \\
\hline$N u_{a v}$ & 8.464 & 8.531 & 8.606 & 8.656 & 8.672 & 8.675 \\
\hline
\end{tabular}

Table2 Comparison of average Nusselt number for different Reynolds number and Grashof number

\begin{tabular}{|c|c|c|c|c|c|c|c|c|}
\hline \multirow[t]{2}{*}{$\operatorname{Re}$} & \multicolumn{4}{|c|}{$\mathrm{Gr}=10^{2}$} & \multicolumn{4}{|c|}{$\mathrm{Gr}=10^{4}$} \\
\hline & a & b & c & $|((b-c) / c) \times 100|$ & a & b & c & $|((b-c) / c) \times 100|$ \\
\hline 400 & 3.84 & 3.85 & 3.91 & $1.53 \%$ & 3.62 & 3.61 & 3.65 & $1.09 \%$ \\
\hline 1000 & 6.33 & 6.33 & 6.33 & $0.00 \%$ & 6.29 & 6.28 & 6.28 & $0.00 \%$ \\
\hline
\end{tabular}

alwatsu et al. [27]; ${ }^{\mathrm{b}}$ Tiwari and Das [28]; ' Present work 
Fig. 3 Grid sensitivity test

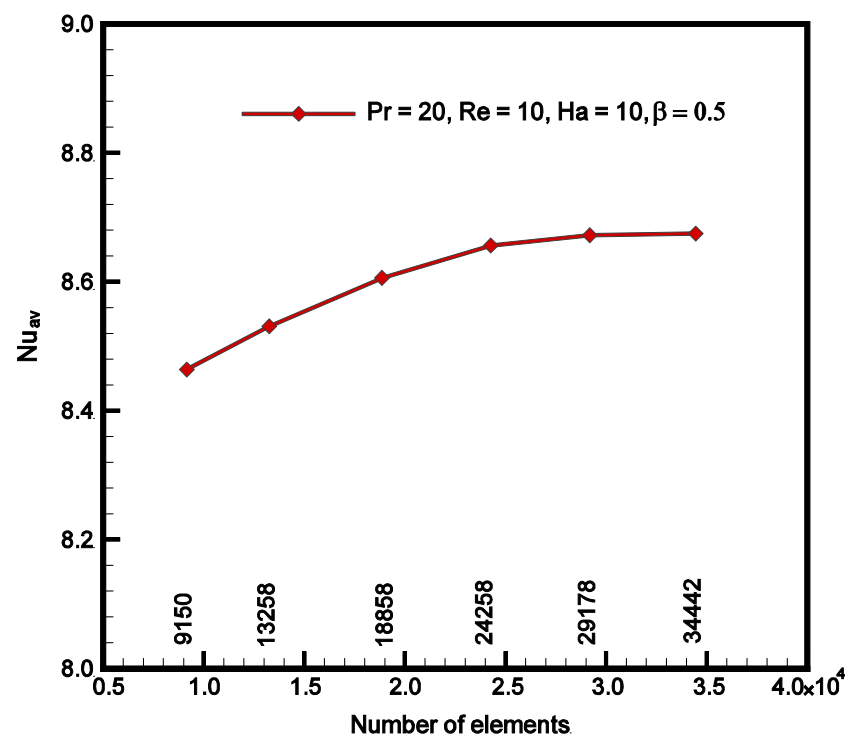

Fig.4 comparison of streamlines (top) and isotherms (bottom) for present results with that of bakar et al. [11]
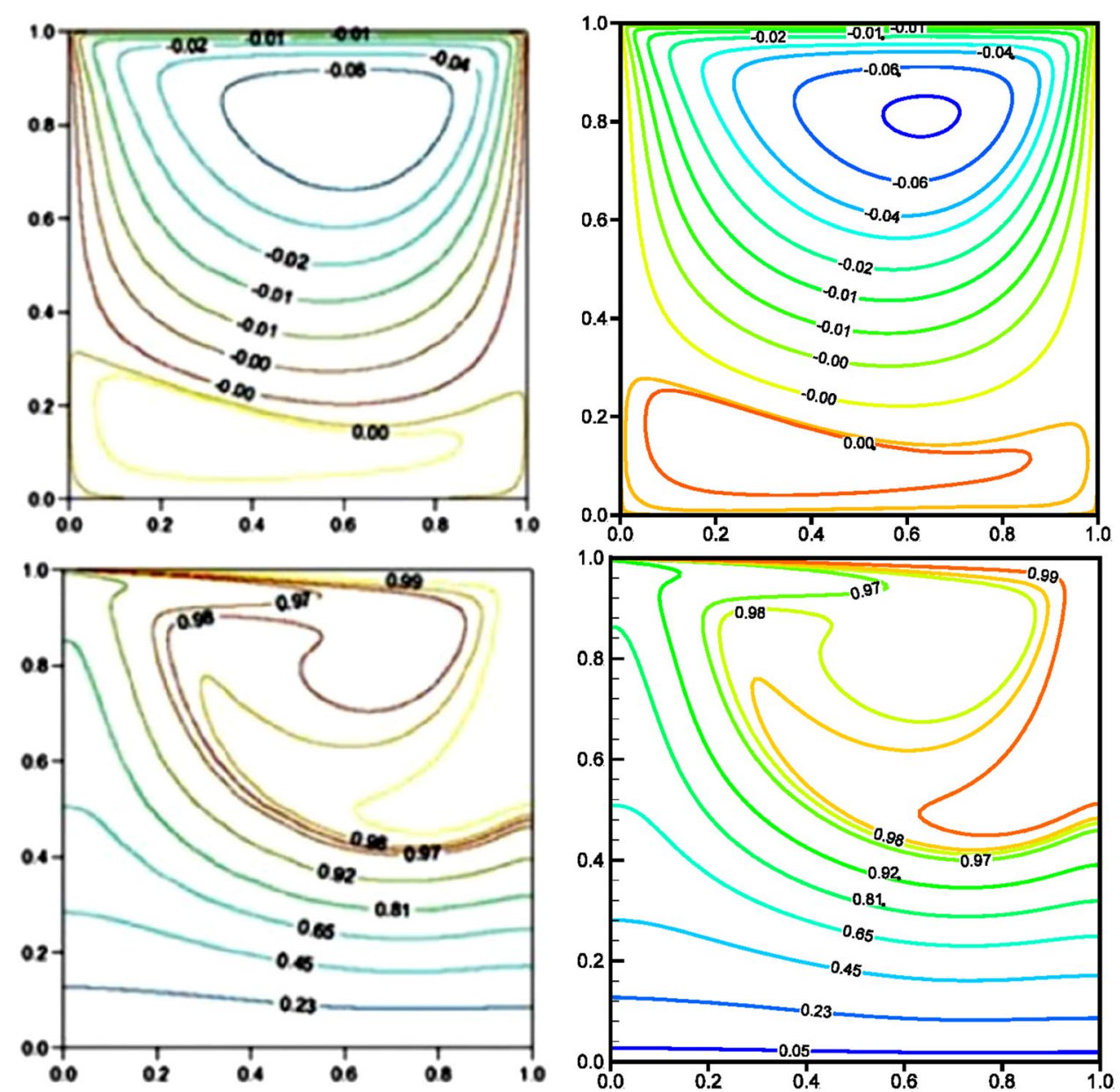
Table 3 Comparison of average Nusselt number $\left(\mathrm{Nu}_{\mathrm{av}}\right)$ for different $\mathrm{Ha}$ and $\phi$ at $\mathrm{Ra}=10^{5}$

\begin{tabular}{lllllllll}
\hline & $\mathrm{a}$ & $\mathrm{b}$ & $\mathrm{a}$ & $\mathrm{b}$ & $\mathrm{a}$ & $\mathrm{b}$ & $\mathrm{a}$ & $\mathrm{b}$ \\
\hline & $\phi=0.00$ & & $\phi=0.02$ & & $\phi=0.04$ & & $\phi=0.06$ & \\
$\mathrm{Ha}=0$ & 4.738 & 4.716 & 4.820 & 4.798 & 4.896 & 4.876 & 4.968 & 4.948 \\
$\mathrm{Ha}=15$ & 4.143 & 4.123 & 4.179 & 4.204 & 4.211 & 4.283 & 4.239 & 4.358 \\
$\mathrm{Ha}=30$ & 3.150 & 3.135 & 3.138 & 3.206 & 3.124 & 3.276 & 3.108 & 3.345 \\
$\mathrm{Ha}=45$ & 2.369 & 2.358 & 2.342 & 2.417 & 2.317 & 2.476 & 2.293 & 2.534 \\
$\mathrm{Ha}=60$ & 1.851 & 1.843 & 1.831 & 1.894 & 1.815 & 1.946 & 1.806 & 1.999 \\
\hline
\end{tabular}

${ }^{\mathrm{a}}$ Gasemi et al. [29] and ${ }^{\mathrm{b}}$ Present study

\subsection{Validation of numerical procedure}

To valid our numerical procedure, we have performed three comparisons using existing results for mixed convection in lid driven cavity and presented as follows:

\subsubsection{Validation case No. 1}

Iwatsu et al. [27] and Tiwari and Das [28] numerically analyzed mixed convection flow in lid driven cavities with different boundary conditions. Comparison of the present results with the comparable results of Iwatsu et al. [27] and Tiwari and Das [28] has been presented in Table 3. It is to be found a rational deflection among the reported data given in Table 3.

\subsubsection{Validation case No. 2}

Ghasemi et al. [29] simulated MHD flow effects on nanofluid natural convection in a square cavity. We have simulated the problem [29] using our code and obtained results are compared in Table 3. A good agreement has been reflected between our numerical results and the results of Ref. [29].

\subsubsection{Validation case No. 3}

Bakar et al. [11] simulated the mixed convection in a lid driven cavity in presence of inclined magnetic field. We have simulated the identical problem of Bakar et al. [11] using our present code. The obtained numerical results are plotted in terms of streamlines and isotherms, and compared with the results of Ref.[11]. This comparison shows an excellent agreement between our results and the results presented by Bakar et al. [11].

These comparisons confirmed us that our numerical procedure provides a considerable accuracy to simulate mixed convection in a Casson fluid filled double lid driven cavity.

\section{Results and discussion}

In this analysis, double lid driven mixed convection in a square cavity filled with Casson fluid has been simulated using finite element method. The effect of magnetic field is considered to control the flow and thermal behaviors within the cavity. The ranges of the important parameters are assumed as Reynolds number (Re) from 1 to 500 , Casson fluid parameter ( $\beta$ ) from 0.1 to 5 and Hartmann number $\mathrm{Ha}$ ) from 0 to 100 for the visualization of fluid motion and temperature distributions. The value of Pransdtl number was fixed at $\operatorname{Pr}=20$ and conductivity ratio of fluid to solid at $K=10$. The flow and temperature fields have been presented via streamlines and isotherms distributions. The heat transfer rate also analyzed in terms of average Nusselt numbers in this section.

The streamline distributions for varying of Re along with the direction of lid walls are presented in Fig. 5. In Fig. 5(a) for case I, the flow circulation is visualized by producing two convection circulations beside the solid obstacle where the left one is rotated in clockwise direction with higher stength as well as elongated shaped compared to right one which is in opposite deection. As Re is increased to 10 in case I, mixed convection is dominant over natural convection which has a negligible effect in flow strenght except the concentration and formation of core cells within the circulations. Further increase in Reynolds number to 100 , forced convection become dominant over mixed convection which controls the distribution of streamlines. In this case $(R e=100)$, streamlines are concentrated with higher strength which reflects a higher rate of convective heat transfer from the heated wall. After that, when Re increased to 500, the core region of each vortices 
Fig. 5 Streamline variation at $\mathbf{a}$ case I and $\mathbf{b}$ case II while $\mathrm{Re}=$ variable, $\beta=0.5, \mathrm{Ha}=10$
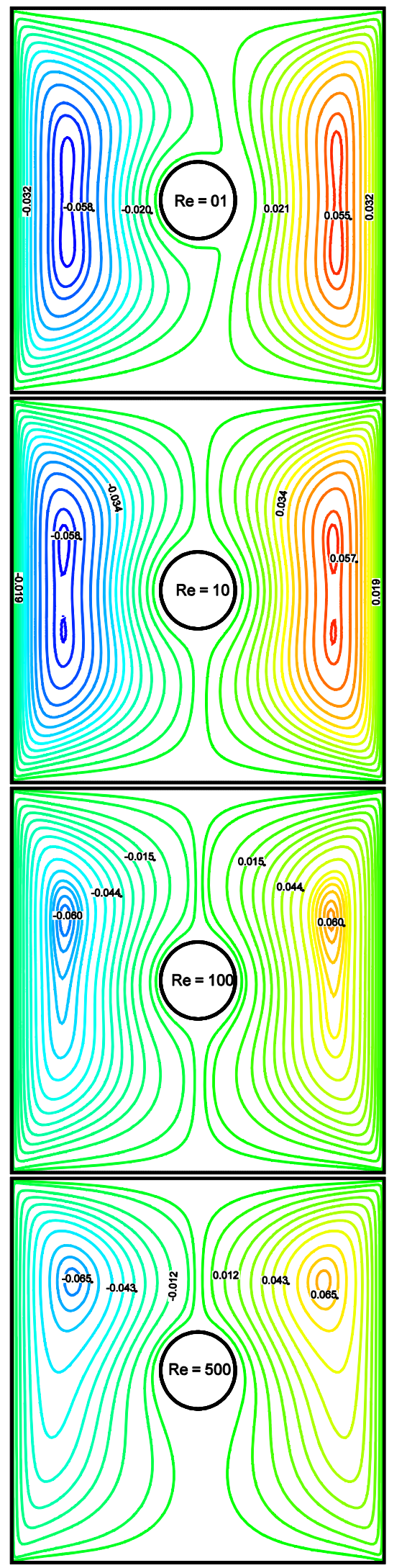

(a)
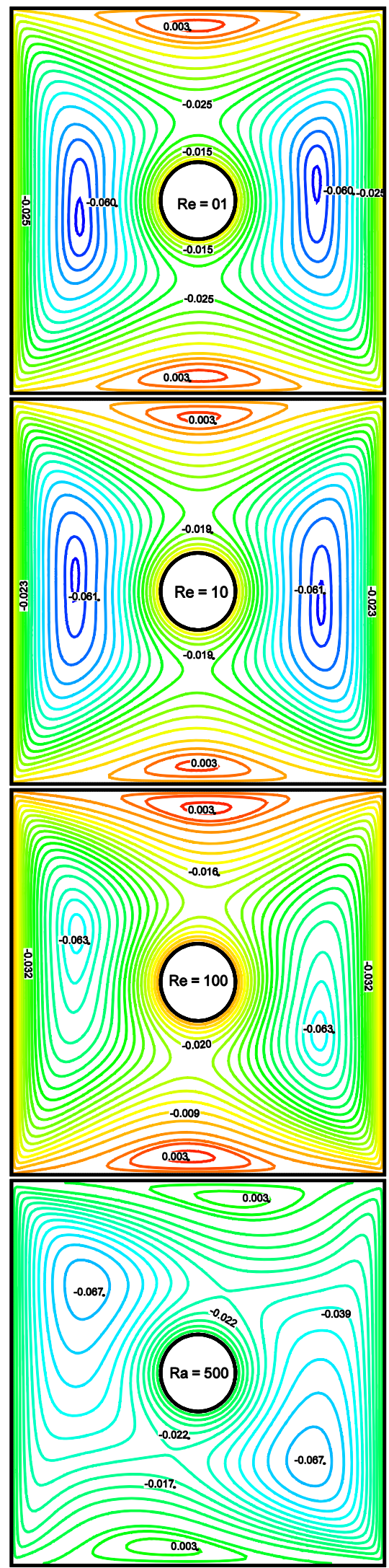

(b) 
Fig. 6 Isotherm variation at $\mathbf{a}$ case I and $\mathbf{b}$ case II while $\mathrm{Re}=$ variable, $\beta=0.5, \mathrm{Ha}=10$
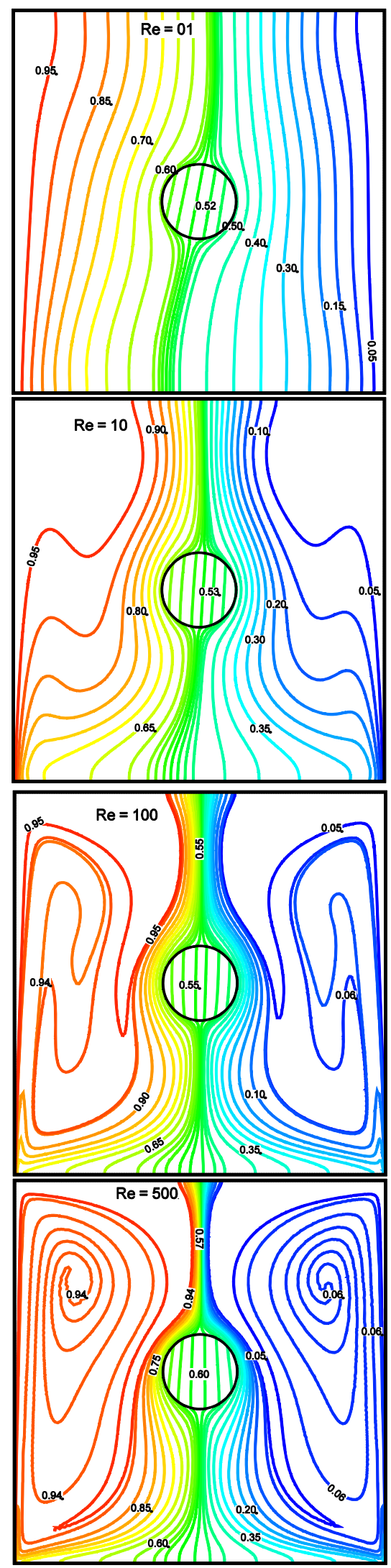

(a)
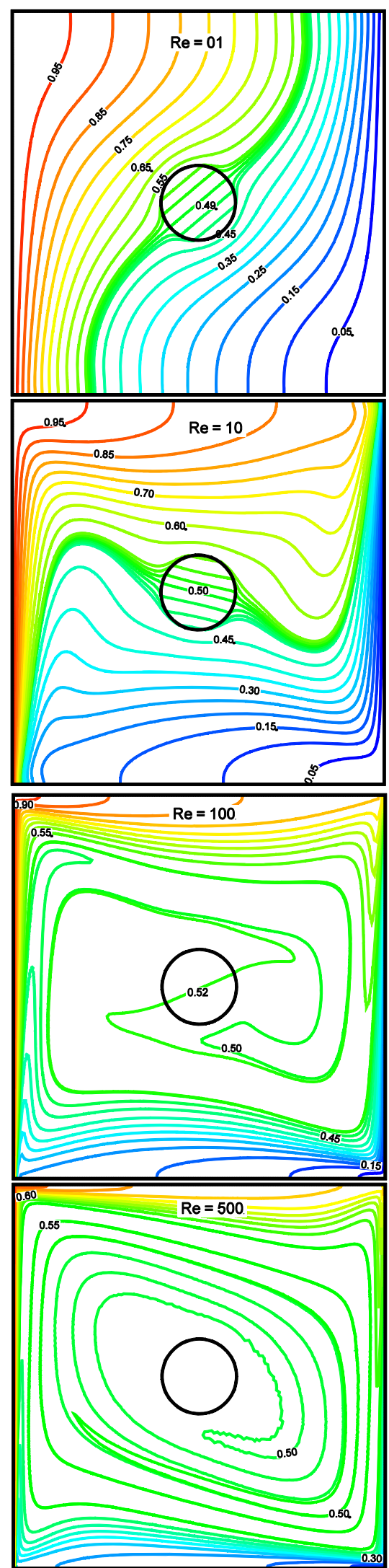

(b) 
shifted upward and gets higher magnetude. This suggests a advanced rate of heat transfer from heated wall. On the other hand, when the lid walls are moved in opposite direction in Fig. 5(b), multipule secondary vortices are generated within and outside the the primary circultions that occupies the whole cavity. It is worth to notice that two seconday circulations are rotated in indentical directions beside the obstacle. The strength and intensification of flow circulation increases remarkebly with increasing of Re as increased Re causes greater fluid inertia. This is an indicative of higher convective heat transfer. Moreover, the flow strength is prominent in case II compared to case I. Thus it is clear that the direction of lid walls plays a vital role in controlling streamlines distributions within the cavity.

Figure 6 represents the isotherm countoutrs for the effcts of Re associated to the different lid wall's directions. When the lid walls move in upward direction in case-l as seen in Fig. 6(a) at $R e=1$, isotherms are emanating from the heated wall and then distributed toward the cold wall. It seems to be almost parallel in vertical direction from heft to right. The red lines corresponds high temperature region near the left moving wall and the blue lines for low temperature region near the right moving wall. From isotherm plotting, it is seen that when the value of $\mathrm{Re}$ increased to 10 , increased fluid inertia tends to dominate the pattern of temperature contours within cavity. As a result, isotherms compressed near middle of the top wall and spread out toward the bottom wall. Further increasing in $\mathrm{Re}$, isotherms are squeezed near the mid section of the cavity and densely bifurcated around the obstacle as well. Moreover, two complicated temperature circulations are also formed besides the condensed isotherms. Further rise in fluid inertia due to higher Re causes fantastic vortices which are symmertic and elongated where central isotherms distribution takes champagne glass shaped. This results led to enhance the heat transfer mechanism significantly. It is impotant to note that the temperature at the core of the solid obstacle gets high values with incresing Re as the thermal conductivity of solid domain decreases with increase in Re. On the other hand, in Fig. 6 (b) the isotherm distribution slitely bended due to the directions of lid walls as described in case II. Moreover, temperature contour tends to condense colse to the left and right vertical walls and parallely dispersed from left to right at $\mathrm{Re}=10$ which leads to increase the heat transfer rate effectively. Further increase in Reynolds number a large isotherms vortex is generated where isotherms are densed near the side walls and more spaced out close to the obstacle. Which leads to increase convective heat transfer rapidely.

Combined effect of Casson fluid parameter and the direction of lid walls on streamlines is presented in Fig. 7.
In Fig. 7(a) at case I, two symmetric circulations are developed beside the obstacle where the right one is stronger compared to the left one. Moreover, the pattern of flow circulation does not change noticiably with increasing $\beta$ except the core region of each circulation. In addition, streamlines are intensified and strength of flow circulation increases considerably for increasing $\beta$ as the increased Casson fluid parameter characterize the additional fluid viscosity which leads to decrease the effective viscosity of working fluid. Accordingly, lower $\beta$ (at $\beta=0.1$ ) causes a lower intensity in streamlines distribution which becomes intensified with greter strength at higher $\beta$ (at $\beta=5$ ) as shown in Fig. 7(a). Besides this, at case II in Fig. 7 (b), the streamlies densely distrubuted by producing two set of eliptic circulations and an annular circulation around the obstacles that occupies the whole cavity. Streamlines pattern almost similar for different values of $\beta$ but an increase in $\beta$ causes an intensification in flow circulations within the cavity. Moreover, strength of fluid motion is accentuated for rising of Casson fluid parameter as seen in Fig. 7 (b).

Figure 8 deleinates isotherm contours for the effect of $\beta$ along with the change in direction of lid walls while the remaining prameters are kept fixed. In Fig. 8 (a), isotherm contours are compactly dictrubuted near the middle of top region and spaced out near the bottom region of the solid cylinder. Denseness of isotherms is visualized close to the middle and solid body comapared to the side regions within the caity. Distribution of isotherms become almost similar with increasing $\beta$ except the solid region. Moreover, temperature at the core of the cylinder reduces with $\beta$ which indicates a higher rate of heat transfer out side the solid blockage. On the other hand, in Fig. 8(b), isotherms distribution affected significantly while the direction of lid wall is changed in opposite direction. It is also observed that these patterns are faintly changed with increasing $\beta$.

The heat transfer rate in terms of average Nusselt number is shown in Fig. 9 and Fig. 10, respectively. In both figures (Fig. 9 and Fig. 10) and cases (case I and case II) heat transfer rate increases consistently with increasing $\mathrm{Re}$. Moreover, when the value Re is considered as unity, heat transfer rate is found to be minimum due to lower fluid inertia and then heat transfer behaviors changes rapidly by increasing Re which was caused by the domination of fluid inertia. In addition, a surprising enhancement in heat transfer rate is observed in case II while the lid walls are moved in opposite direction as seen in Fig. 9(b). It is important to note that the increment of heat transfer in case II become almost five times compared to the case I. In Fig. 9 (a), average Nusselt number becomes highest while magnetic field was not considered. After that, while magnetic field effect was considered at $\mathrm{Ha}=10$, it gets lower values and then average Nusselt number becomes minimum at higher strength of magnetic field. The effect of 
Fig. 7 Streamline variation at $\mathbf{a}$ case I and $\mathbf{b}$ case II while $\mathrm{Re}=$ variable, $\beta=0.5, \mathrm{Ha}=10$
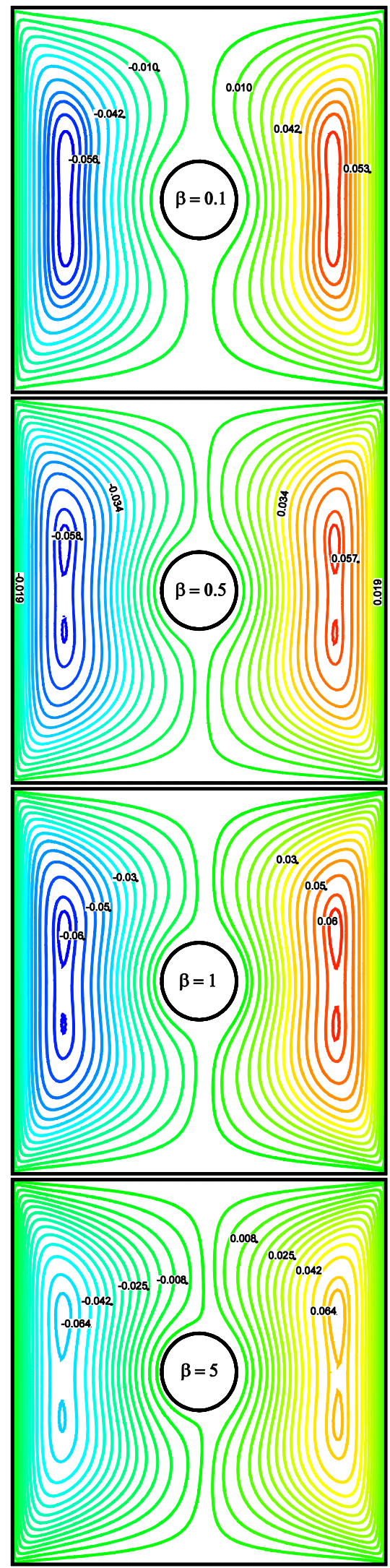

(a)

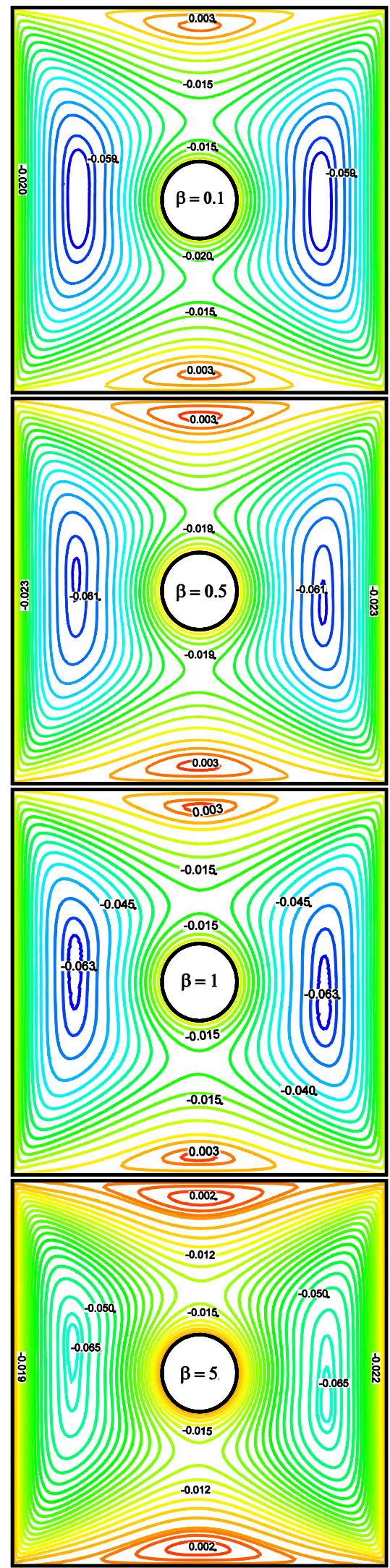

(b) 
Fig. 8 Isotherm variation at $\mathbf{a}$ case I and $\mathbf{b}$ case II while $\mathrm{Re}=$ variable, $\beta=0.5, \mathrm{Ha}=10$
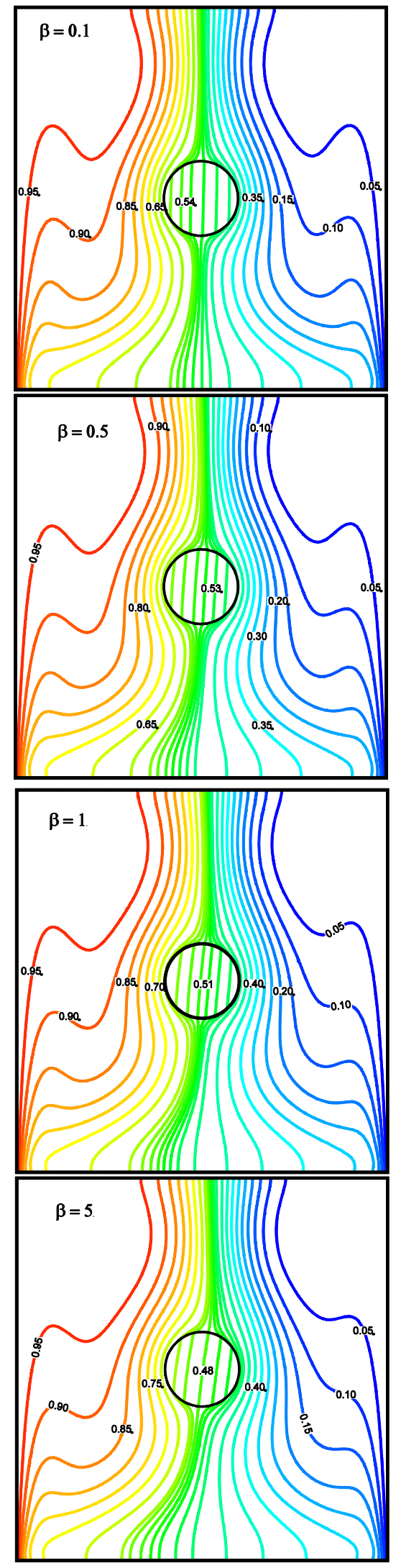

(a)
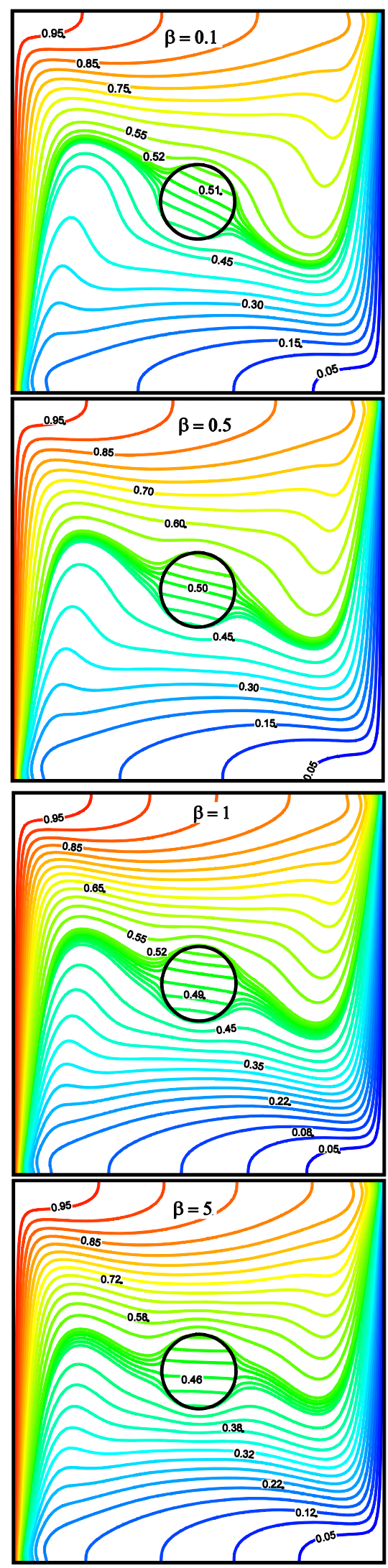

(b) 


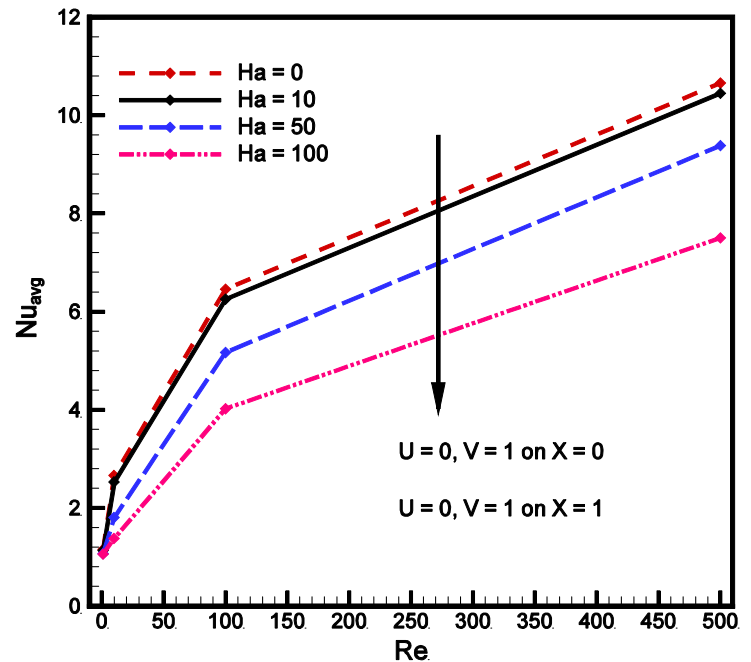

(a)

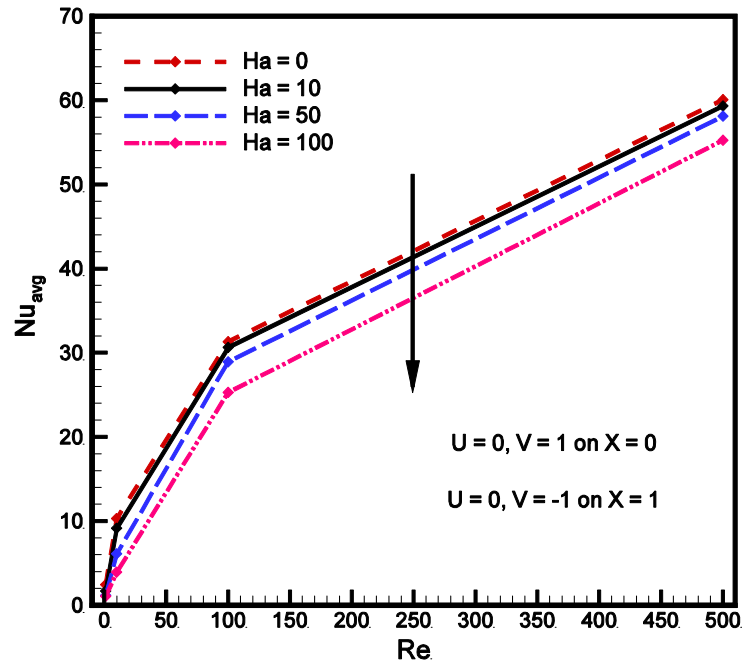

(b)

Fig. 9 Average Nusselt number variation at $\mathbf{a}$ case I and $\mathbf{b}$ case II while $\mathrm{Re}=$ variable, $\mathrm{Ha}=$ variable $\beta=0.5$

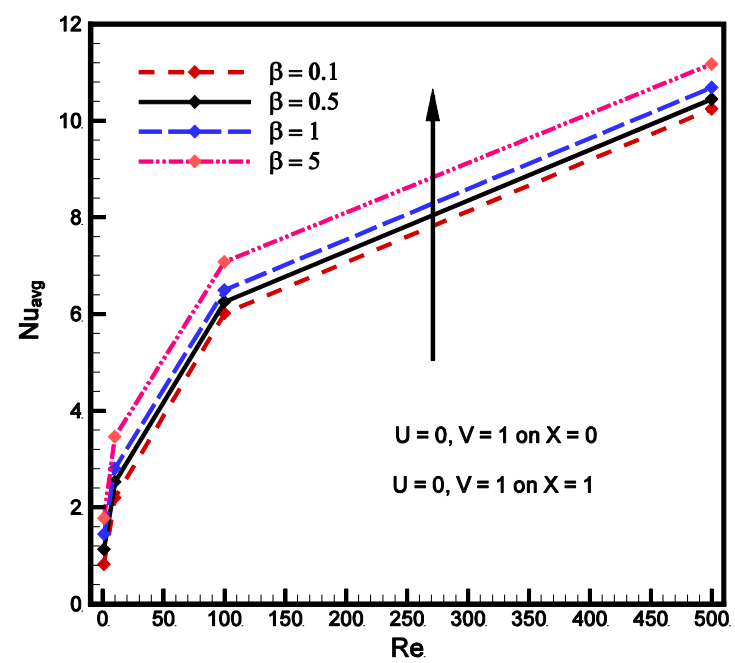

(a)

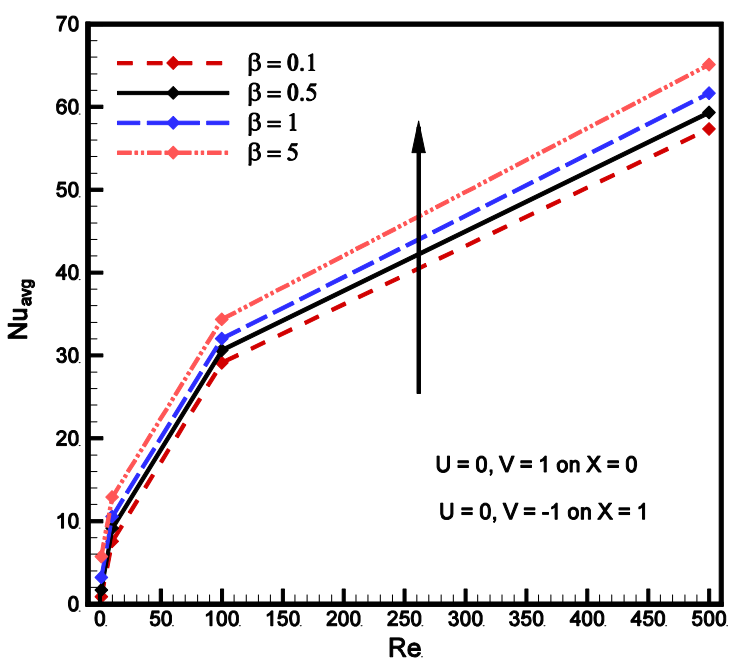

(b)

Fig. 10 Average Nusselt number variation at $\mathbf{a}$ case $\mathrm{I}$ and $\mathbf{b}$ case II while $\mathrm{Re}=$ variable, $\beta=$ variable and $\mathrm{Ha}=10$

magnetic field on heat transfer rate due to Re dominated by the direction of lid walls as the heat transfer decreases by $29.63 \%$ in case I whereas it becomes $8.05 \%$ in case II. On the other hand, augmentation of heat transfer rate due to Re essentially accelerates with an increase in Casson fluid parameter in both cases as seen in Fig. 10. The physics behind its that flow circulation is intensified with increase in $\beta$ and also the direction of lid walls. The numerical results confirmed that heat transfer rate increases by $9.05 \% \%$ in case I while the values of $\beta$ varies from 0.1 to 5 at $\mathrm{Re}=500$ whereas it becomes $13.59 \%$ in the case II which also indicates a domination of the direction of lid walls on the heat transfer rate.

\section{Conclusion}

In this paper, the problem of mixed convection in a Casson fluid filled double lid driven cavity having a solid obstacle under the effect of magnetic field is numerically studied. The finite element method has been used to solve the governing partial differential equations. Comparisons against 
the previously published works on the basis of special cases have been performed and found to be in rational agreements. Obtained numerical results have been discussed precisely from the technological point of view. The major findings of this investigation can be highlighted as follows:

- Flow strength accelerates with the increase of Reynolds number and Casson fluid parameter, and decelerates for increasing of magnetic parameter.

- Temperature distribution modified noticeably with higher Re while it remains uniform for varying of $\beta$.

- Heat transfer rate enhances with rising Re while it reduces for magnetic field.

- The increase in Casson fluid parameter enhances the heat transfer rate effectively.

- Flow circulation and temperature distribution are influenced significantly in the direction of lid walls.

- Heat transfer rate is maximum while lid walls move in opposite direction.

- Present investigation is carried out for advanced practical applications of non-Newtonian Casson fluid. As our study is a numerical investigation, experimental work is required for more validation and effectiveness of the simulated findings.

\section{Compliance with ethical standards}

Conflicts of Interest The authors declare no conflict of interest.

Open Access This article is licensed under a Creative Commons Attribution 4.0 International License, which permits use, sharing, adaptation, distribution and reproduction in any medium or format, as long as you give appropriate credit to the original author(s) and the source, provide a link to the Creative Commons licence, and indicate if changes were made. The images or other third party material in this article are included in the article's Creative Commons licence, unless indicated otherwise in a credit line to the material. If material is not included in the article's Creative Commons licence and your intended use is not permitted by statutory regulation or exceeds the permitted use, you will need to obtain permission directly from the copyright holder. To view a copy of this licence, visit http://creativecommons .org/licenses/by/4.0/.

\section{References}

1. Basak T, Roy S, Sharma PK, Pop I (2009) Analysis of mixed convection flows within a square cavity with uniform and non-uniform heating of bottom wall. Int J Therm Sci 48(5):891-912
2. Mahmoodi M (2011) Mixed convection inside nanofluid filled rectangular enclosures with moving bottom wall. Thermal Sci 15(3):889-903

3. Fereidoon A, Saedodin S, Hemmat Esfe M, Noroozi MJ (2013) Evaluation of mixed convection in inclined square lid-driven cavity filled with Al203/water nano-fluid. Eng Appl Comput Fluid Mechanics 7(1):55-65

4. Abu-Nada E, Chamkha AJ (2014) Mixed convection flow of a nanofluid in a lid-driven cavity with a wavy wall. Int Commun Heat Mass Transfer 57:36-47

5. Ekici Ö (2018) Lattice boltzmann simulation of mixed convection heat transfer in a lid-driven square cavity filled with nanofluid: a revisit. J Heat Transf 140(7):072501. https://doi. org/10.1115/1.4039490

6. Rabani M (2019) Numerical analysis of mixed convection heat transfer in a triangular cavity with moving walls. Heat Transf Res 50(5):463-485

7. Alsabery Al, Selimefendigil F, Hashim I, Chamkha AJ, Ghalambaz $M$ (2019) Fluid-structure interaction analysis of entropy generation and mixed convection inside a cavity with flexible right wall and heated rotating cylinder. Int J Heat Mass Transf 140:331-345

8. Ali MM, Alim MA, Ahmed SS (2017) Magnetohydrodynamic mixed convection flow in a hexagonal enclosure. Procedia Eng 194:479-486

9. Ali MM, Alim MA, Ahmed SS (2018) Numerical simulation of hydromagnetic natural convection flow in a grooved enclosure filled with $\mathrm{CuO}$-water nanofluid considering Brownian motion. Int J Appl Comput Math 4(5):125

10. Selimefendigil F, Öztop HF (2014) Numerical study of MHD mixed convection in a nanofluid filled lid driven square enclosure with a rotating cylinder. Int J Heat Mass Transf 78:741-754

11. Bakar NA, Roslan R, Hashim I (2019) Mixed convection in liddriven cavity with inclined magnetic field. Sains Malaysiana 48(2):451-471

12. Selimefendigil F, Öztop HF (2015) Numerical study and podbased prediction of natural convection in a ferrofluids-filled triangular cavity with generalized neural networks. Numer Heat Transf, Part A: Appl 67(10):1136-1161

13. Selimefendigil F, Öztop HF (2019) MHD Pulsating forced convection of nanofluid over parallel plates with blocks in a channel. Int J Mech Sci 157:726-740

14. Selimefendigil F, Öztop HF (2020) Combined effects of double rotating cones and magnetic field on the mixed convection of nanofluid in a porous 3D U-bend. Int Commun Heat Mass Transf 116:104703

15. House JM, Beckermann C, Smith TF (1990) Effect of a centered conducting body on natural convection heat transfer in an enclosure. Numer Heat Transf 18(2):213-225

16. Rahman MM, Alim MA, Mamun MAH (2009) Finite element analysis of mixed convection in a rectangular cavity with a heatconducting horizontal circular cylinder. Nonlinear Anal: Modell Control 14(2):217-247

17. Islam AW, Sharif MA, Carlson ES (2012) Mixed convection in a lid driven square cavity with an isothermally heated square blockage inside. Int J Heat Mass Transf 55(19-20):5244-5255

18. Bourada A, Bouarnouna K, Boutra A, Benzema M, Benkahla YK (2019, April) Numerical simulation of mixed convection in a lid driven cavity with porous obstacle using (MRT-LBM). In 2nd national conference on computational fluid dynamics \& technology 2018 (CFD \& Tech 2018). https://doi.org/10.2139/ ssrn.3373767 
19. Pop I, Sheremet M (2017) Free convection in a square cavity filled with a Casson fluid under the effects of thermal radiation and viscous dissipation. Int J Numer Methods Heat Fluid Flow 27(10):2318-2332

20. Reddy GJ, Kethireddy B, Kumar M, Rani HP, Gorla RSR (2018) Effect of Prandtl number for casson fluid flow over a vertical cylinder: heatline approach. Int J Appl Comput Math 4(3):85

21. Hamid M, Usman M, Khan ZH, Haq RU, Wang W (2019) Heat transfer and flow analysis of Casson fluid enclosed in a partially heated trapezoidal cavity. Int Commun Heat Mass Transfer 108:104284

22. Raza J, Rohni AM, Omar Z (2016) Multiple solutions of mixed convective MHD casson fluid flow in a channel. J Appl Math. https://doi.org/10.1155/2016/7535793

23. Nasrin R, Alim MA, Chamkha AJ (2012) Buoyancy-driven heat transfer of water-AI 203 nanofluid in a closed chamber: effects of solid volume fraction, Prandtl number and aspect ratio. Int J Heat Mass Transf 55(25-26):7355-7365

24. Bunch JR, Hopcroft JE (1974) Triangular factorization and inversion by fast matrix multiplication. Math Comput 28(125):231-236
25. Taylor C, Hood P (1973) A numerical solution of the NavierStokes equations using the finite element technique. Comput Fluids 1:73-89

26. Dechaumphai P (1999) Finite Element Method in Engineering, 2nd edn. Chulalongkorn University Press, Bangkok

27. Iwatsu R, Hyun JM, Kuwahara K (1993) Mixed convection in a driven cavity with a stable vertical temperature gradient. Int J Heat Mass Transf 36(6):1601-1608

28. Tiwari RK, Das MK (2007) Heat transfer augmentation in a twosided lid-driven differentially heated square cavity utilizing nanofluids. Int J Heat Mass Transf 50(9-10):2002-2018

29. Ghasemi B, Aminossadati SM, Raisi A (2011) Magnetic field effect on natural convection in a nanofluid-filled square enclosure. Int J Therm Sci 50(9):1748-1756

Publisher's Note Springer Nature remains neutral with regard to jurisdictional claims in published maps and institutional affiliations. 